\section{HOW BADLY MUST A REGULATOR PERFORM BEFORE SOMEONE INTERVENES, ASKS BDA}

The British Dental Association (BDA) is concerned that the General Dental Council (GDC) has come bottom of the league in an assessment of the performance of nine healthcare regulators, published today by the Professional Standards Authority (PSA).

The PSA highlights that the GDC failed to meet a total of seven of its standards of good regulation. On fitness to practise, the GDC fully met only one of the 10 standards, and failed to meet six others, representing what the PSA describes as a significant decline in its performance compared to an assessment it carried out in 2013/14.

The BDA notes that the jury couldn't decide on whether the GDC had met two additional standards on fitness to practise pending an ongoing enquiry by the PSA.

The PSA has yet to comment on whether it considers the GDC's activities in this area are 'transparent, fair, proportionate and focused on public protection'.

Commenting on the PSA report, BDA Chair Mick Armstrong, said: 'Sadly this report makes familiar reading. Yet again GDC registrants must acknowledge that they are being regulated by the worst health regulator in the UK. What is worse is that, as far as dentists are concerned, it is now also the most expensive by a country mile.

'The findings in relation to fitness to practise come as little surprise as stories of waste, mismanagement and unreasonable practices abound.

'It is difficult to understand how badly the GDC has to perform before someone actually intervenes.'

Responding to the review, the GDC said 'Today's PSA report confirms that in the areas of guidance and standards, education and training, and registration the GDC is performing well. However, we also recognise that the PSA has identified a number of areas within the Fitness to Practise (FtP) category where reform is required.

\section{MY DENTIST GAVE ME IDEA FOR NEW SUGAR FREE BAKING BOOK AND CAKES FROMTHE TOOTH FAIRY, SAYS POPULAR BAKER SUGAR FREE BAKING}

,

SUGAR FREE

BAKING her dentist Murray Hawkins, focuses on recipes that use xylitol as a natural sugar substitute - a product that also has known benefits for the preservation of healthy teeth.

A foreword written by celebrity chef Gary Rhodes says, 'Reading this book inspired in me a hunger to cook and nibble amongst the many sweet fancies presented. It is even more of a pleasure to read how xylitol creates ' a sweet bite we can all enjoy.'

Sue Simkins said: 'At the same time as baking is seeing a surge in popularity, there have also been a number of reports about the negative effects sugar has on our bodies and teeth. The approach and the recipes I have provided in Sugar Free Baking and Cakes from the Tooth Fairy mean everyone can try their hand at baking without worrying about the effects on their waist line or their health.'

Sugar Free Baking is published by Constable Robinson and is available from Amazon at £7.99. Sue Simkins' other titles include Cakes from the Tooth Fairy, Tea with Mrs Simkins, Cooking with Mrs Simkins, Fresh Bread \& Bakes from your Bread Machine, Afternoon Tea and How to Make the Most of Your Food Processor.

For further information and recipes, visit www.mrssimkins.co.uk.

\section{HOLYROODTO} REGULATE PRIVATE CLINICS

Private clinics carrying out procedures such as Botox injections and teeth whitening are to be regulated from next year, the Scottish Government has announced. Legislation is to be brought in at Holyrood to allow Healthcare Improvement Scotland to start regulating private clinics where non-surgical cosmetic procedures are carried out from April.

There is currently no regulation for such centres - which also offer procedures such as laser eye surgery and dermal fillers - anywhere in the UK.

Around one in five Scots have either had a private cosmetic procedure or have thought about having one. Public Health Minister Maureen Watt said: 'Cosmetic procedures, both surgical and non-surgical, have increased massively in popularity over the last few years.

'Many people are not aware that there is no regulation of independent clinics who provide non-surgical cosmetic procedures.

'There are many reputable practitioners in Scotland, but unfortunately there are others who do not live up to those high standards.

'That can lead to complications after procedures, sometimes leaving the customer with lasting injuries. By introducing a sound system of regulation and inspection we hope to reduce those instances.'

\section{Have}

\section{your say on CPP}

Are you interested in having your say on CPD? Then you will be glad to know UCL Eastman are carrying out a nationwide survey to find out your views on the current state of CPD. To fill in the online survey, click here. 